\title{
Thallium-201 scintigraphy in the evaluation of graft dysfunction in lung transplantation
}

\author{
M.S. Karetzky, R.R. Jasani, M.A. Zubair and \\ Newark Beth Israel Medical Center Lung Transplant Group
}

Thallium-201 scintigraphy in the evaluation of graft dysfunction in lung transplantation. M.S. Karetzky, R.R. Jasani, M.A. Zubair and Newark Beth Israel Medical Center Lung Transplant Group. (CERS Journals Ltd 1996.

ABSTRACT: The object of this study was to evaluate graft dysfunction utilizing thallium-201 scintigraphy in patients who had undergone lung transplantation.

We studied 11 patients who had undergone single-lung transplantation and had 44 evaluations for suspected graft dysfunction. All evaluations included a lung thallium-201 scan and chest radiography. In addition, 42 transbronchial biopsies, 19 gallium-67 scans and 28 pulmonary function tests were obtained. Rejection was defined by histopathology and/or the response to an empirical pulse of methylprednisolone, while cultures of protected specimen brushes and blood with a positive chest radiograph were used to define infection.

The sensitivity of thallium scintigraphy for diagnosing rejection and/or infection (94\%) was higher than that for transbronchial biopsy $(\mathbf{8 6 \%})$, gallium scintigraphy $(47 \%)$, chest radiography $(67 \%)$, or spirometry testing $(30 \%)$. Specificity was $100 \%$ for thallium scintigraphy and transbronchial biopsy, as compared to chest radiography and spirometry, which were 75 and $80 \%$ respectively.

This study indicated that thallium-201 scintigraphy is useful for screening lung transplant recipients for episodes of acute rejection and/or infection. A positive scan is confirmation of graft parenchymal dysfunction and may then be followed by empirical treatment or bronchoscopy with transbronchial biopsy and culture to differentiate rejection and infection.

Eur Respir J., 1996, 9, 2553-2559.
Pulmonary and Critical Care Division, Newark Beth Israel Medical Center and the New Jersey School of Medicine, University of Medicine and Dentistry of New Jersey, Newark, NJ, USA.

Correspondence: M. Karetzky Newark Beth Israel Medical Center 201 Lyons Avenue

Newark

NJ-07112

USA

Keywords: Gallium scintigraphy lung transplantation

nuclear imaging

rejection

thallium scintigraphy

transbronchial biopsy

Received: February 231996

Accepted after revision August 171996
While acute rejection is a common event, the shortterm survival of lung transplant recipients is primarily influenced by episodes of infection [1]. The goal of surveillance for acute graft dysfunction in the immediate postoperative period is, therefore, both early detection of infection and its differentiation from rejection. The clinical and noninvasive methods of organ assessment, including physical examination, spirometry (pulmonary function tests (PFTs)), chest radiography, high resolution computed tomography (HRCT), and single photon emission computed tomography (SPECT), are either insensitive, nonspecific, or not cost-effective for detecting pulmonary rejection or infection in this population [2-7].

Bronchoscopy with transbronchial biopsy (TBB), therefore, remains the standard for the detection and differentiation of rejection from infection. In previous studies, the specificity and sensitivity of TBB in the diagnosis of rejection after lung transplantation has been reported as being as high as 90 and $100 \%$, respectively [8]. However, it has been suggested, because of data indicating a false negative rate as high as $28 \%$ in identifying acute rejection [9], that clinical improvement with antirejection treatment with or without histological changes be used to diagnose rejection [3]. This has proved to be an attractive alternative, since transbronchial biopsy has a high cost and an established morbidity and mortality [10]. Similarly, whilst bronchoalveolar lavage (BAL) has also been a useful technique for diagnosing infection, empirical antimicrobial protocols have been used for diagnostic as well as therapeutic trials.

Our previous experience with thallium-201 $\left.{ }^{201} \mathrm{Tl}\right)$ scintigraphy has indicated its value in a variety of inflammatory lung diseases [11]. Therefore, we evaluated ${ }^{201} \mathrm{Tl}$ scintigraphy as a readily available, sensitive and noninvasive method to guide further diagnostic testing in symptomatic patients with a transplanted lung for determining the presence of lung rejection or infection.

\section{Methods}

We prospectively studied 11 single-lung transplant recipients who underwent 44 evaluations for suspected graft dysfunction. All evaluations consisted of ${ }^{201} \mathrm{Tl}$ scintigraphy and routine chest radiography (CXR), and 42 bronchoscopies with TBB and culture, 19 Gallium$67\left({ }^{67} \mathrm{Ga}\right)$ scans, and 28 spirometric studies were also performed. All investigations were carried out within a $48 \mathrm{~h}$ period of evaluation prior to starting empirical 
treatment. Investigations performed within a week posttransplantation were excluded from the study to eliminate patients with an "implantation response". Graft dysfunction was defined as the presence of fever, cough, shortness of breath, and/or worsening hypoxaemia. Rejection was defined by histopathological changes and/or sustained improvement in clinical symptoms, radiological signs, and abnormalities in blood gas values after aggressive immunosuppresive high-dose corticosteroid therapy. The criteria used to define infection were: positive quantitative cultures of protected brush specimens (PBS) obtained during bronchoscopy; positive blood culture with new or changing infiltrates on CXR or transbronchial biopsy showing viral inclusions, or invasive fungal disease.

Thallium-201 scintigraphy was performed according to the following protocol. Patients first received 2-3 $\mathrm{mCi}$ of thallous chloride-201 intravenously. Imaging was performed 5 min later with a stationary large field of view camera equipped with a low energy collimator. The patient then received $6-7 \mathrm{mCi}$ of gallium-67 citrate, with imaging performed at $72 \mathrm{~h}$ with the same camera using a high energy collimator. Each scan was prospectively analysed by two blinded nuclear radiologists, who rendered a single consensus opinion. The following scales were used to grade the pulmonary abnormalities for thallium scans: $0=$ no pulmonary activity above soft tissue background; $1=$ pulmonary activity above soft tissue background; $2=$ pulmonary activity less than that of the heart; $3=$ pulmonary activity intermediate between grades 2 and 4; and 4=pulmonary activity equal to or greater than that of the heart. Gallium scans of the chest were graded as follows: $0=$ no pulmonary activity above soft tissue background; $1=$ pulmonary activity above soft tissue background; $2=$ pulmonary activity less intense than that of the sternum; $3=$ pulmonary activity equal to that of the sternum; and 4=pulmonary activity greater than that of the sternum. A normal scan was defined as a reading of 0 , and an abnormal scan indicating pulmonary abnormality as grades $1,2,3$ or 4 . The scans were routinely compared with the CXR.

Pulmonary function tests (PFT) were evaluated according to the Working Formulation for the Standardization of Nomenclature and for Clinical Staging of Chronic Dysfunction in Lung Allografts [12]. The most reliable and consistent value of the PFT considered positive for suspected graft dysfunction was a forced expiratory volume in one second (FEV1) with a $20 \%$ or greater decline from baseline.

Bronchoscopy using a flexible fibreoptic bronchoscope, with TBB and culture of the lower airways was performed, using a PSB, for diagnosis if lung rejection or infection was suspected. Five TBB specimens were obtained under fluoroscopic guidance from different segments of the graft. All biopsies were reviewed by a single experienced lung pathologist unaware of scintigraphic findings. Specimens, fixed in formalin and imbedded in paraffin, were serially sectioned and routinely stained with haemaluneosine-safran, Perls' stain for siderophages, periodic-acid-Schiff (PAS) and Gomori-Grocott stains for mycosis and parasites, and trichrome stain for fibrosis, as well as immunofluorescence, immunoperoxidase and histological methodologies for cytomegalovirus (CMV). The TBB was interpreted according to the working formulation for the standardization of nomenclature in the diagnosis of lung rejection [13]. TBB and cultures were interpreted in absolute terms as either positive or negative for rejection and/or infection.

Identification of bacterial pathogens was made, in the presence of a positive radiograph, from cultures of blood or the bronchoscopy specimens from the lower airways. Blood cultures were performed, using the Bactec $6 \mathrm{~A}$ system. PSB with cultures exhibiting greater than $10^{3}$ colony forming units (cfu) of any single organism were considered diagnostic of bacterial infection [14]. Determination of specific immunoglobulin $\mathrm{M}(\operatorname{IgM})$ and immunoglobulin $\mathrm{G}(\mathrm{IgG})$ in response to $\mathrm{CMV}$ was performed by enzyme-linked immunosorbent assay.

All patients received immunosuppression according to a standard protocol. Intravenous methylprednisolone $(500 \mathrm{mg})$ was given intraoperatively at the time of transplantation, followed by $100 \mathrm{mg}$ intravenously b.i.d. and a tapering regimen over 2 weeks to $0.3 \mathrm{mg} \cdot \mathrm{kg}^{-1}$ q.d. of prednisone equivalent. Cyclosporin was given at a dose of $5 \mathrm{mg} \cdot \mathrm{kg}^{-1}$ preoperatively, followed by adjusted dosing every $12 \mathrm{~h}$ to maintain levels of $300 \mathrm{ng} \cdot \mathrm{mL}^{-1}$. Cyclosporin levels were measured by high performance liquid chromatography on a whole blood sample [15]. Azathioprine was given at $2 \mathrm{mg} \cdot \mathrm{kg}^{-1}$ q.d., adjusted to maintain a white blood cell count of about $6 \times 10^{9}$ cells $\cdot \mathrm{L}^{-1}$. An induction regimen of $5 \mathrm{mg} \cdot \mathrm{kg}^{-1}$ q.d. antithymocyte gammaglobulin (ATGAM) was used immediately post-transplant over a period of 5-7 days. Immunosuppression was maintained in a standard triple therapy regimen, consisting of cyclosporin, azathioprine and oral prednisolone. Episodes of rejection were treated with pulsed methylprednisolone, at a dose of $10 \mathrm{mg} \cdot \mathrm{kg}^{-1}$ for 3 days, followed by oral prednisolone at $1 \mathrm{mg} \cdot \mathrm{kg}^{-1}$ q.d., weaning to the maintenance dose over 4 weeks. An infection prophylaxis protocol that was utilized included a double strength tablet of trimethoprim/sulphamethoxazole three times a week, $800 \mathrm{mg}$ of acyclovir every $8 \mathrm{~h}$, and gancyclovir at $5 \mathrm{mg} \cdot \mathrm{kg}^{-1}$ every $12 \mathrm{~h}$ intravenously for 2 weeks in patients at risk for CMV infection.

Data analysis was performed for comparison of thallium-201 scan, bronchoscopy with TBB and PSB, CXR, FEV1 and gallium-67 scan on all admissions. Sensitivity, specificity, diagnostic accuracy and predictive values of positive (PPV) and negative (NPV) tests were calculated using standard formulae [16].

\section{Results}

There were 11 patients, 7 males and 4 females, with a mean age of 54 yrs (range 35-67 yrs) and mean follow-up period of 19 months (range 4-35 months). The primary patient diagnoses were: eight chronic obstructive pulmonary disease (COPD); one primary pulmonary hypertension; one idiopathic pulmonary fibrosis; and one pulmonary eosinophilic granuloma. Eight patients received right and three left lung transplants from 29 June 1992 to 10 February 1995. Currently, nine patients are alive whilst two died, one due to infection and rejection and another due to rejection. Clinical characteristics of all patients are shown in table 1. 
Table 1. - Clinical characteristics of patients

\begin{tabular}{rccccccc}
\hline $\begin{array}{c}\text { Pts } \\
\text { No. }\end{array}$ & $\begin{array}{c}\text { Age } \\
\text { yrs }\end{array}$ & Sex & Race & $\begin{array}{c}\text { Primary } \\
\text { diagnosis }\end{array}$ & $\begin{array}{c}\text { Donor } \\
\text { lung }\end{array}$ & $\begin{array}{c}\text { Follow-up } \\
\text { months }\end{array}$ & $\begin{array}{c}\text { Current } \\
\text { status }\end{array}$ \\
\hline 1 & 46 & M & W & PPH & Rt & 32 & A \\
2 & 42 & M & H & COPD & Rt & 28 & D \\
3 & 35 & F & W & PEG & Lt & 24 & A \\
4 & 62 & M & W & COPD & Rt & 21 & A \\
5 & 60 & M & W & COPD & Rt & 21 & A \\
6 & 52 & F & B & IPF & Lt & 15 & A \\
7 & 48 & F & B & COPD & Rt & 13 & A \\
8 & 59 & F & W & COPD & Rt & 11 & A \\
9 & 64 & M & W & COPD & Rt & 6 & D \\
10 & 60 & M & B & COPD & Lt & 4 & A \\
11 & 67 & M & B & COPD & Rt & 1 & A \\
\hline
\end{tabular}

Pts: patients; M: male; F: female; W: white; B: black; H: hispanic; A: alive; D: dead; COPD: chronic obstructive pulmonary disease; IPF: idiopathic pulmonary fibrosis; PPH: primary pulmonary hypertension; PEG: pulmonary eosinophilic granuloma; Rt: right; Lt: left.

There were 44 evaluations for symptoms suggestive of acute graft dysfunction. All had $201 \mathrm{Tl}$ scintigraphy and CXR, 19 had ${ }^{67} \mathrm{Ga}$ scans, while 42 had bronchoscopies with TBB and quantitative plug-tip culture, and 28 had appropriately paired (post-transplant and pretreatment) PFT studies. There were 18 episodes of isolated rejection, 10 of isolated infection, eight had both rejection and infection and eight had no evidence of an active process. The diagnostic investigations, results and diagnoses are shown in table 2. Thirty four ${ }^{201} \mathrm{Tl}$ scans were positive, 16 were associated with rejection, 10 with infection, and eight with rejection and infection. A patient with rejection showing $2+$ positive ${ }^{201} \mathrm{Tl}$ scan is shown in figure 1 , in contrast to another with a negative scan in figure 2 without any infection or rejection. Thirty TBBs with plug-tip culture were positive, 16 showed rejection, six showed infection, and eight showed rejection and infection. Eight ${ }^{67} \mathrm{Ga}$ scans were positive, one was associated with rejection, five with infection, and two with rejection and infection. Twenty six CXR were abnormal, 11 were associated with rejection, eight with infection, five with rejection and infection, and two without any rejection or infection. Eight evaluations showed deterioration of pulmonary function, four were associated with rejection, two with infection, one with rejection and infection, and one without rejection or infection.

Table 2. - Results of all diagnostic procedures and diagnosis

\begin{tabular}{lcccccr}
\hline & $\mathrm{R}$ & $\mathrm{I}$ & $\mathrm{R}+\mathrm{I}$ & $\mathrm{R}$ and/or I & No & Total \\
\hline${ }^{201} \mathrm{Tl}+/ \mathrm{n}$ & $16 / 18$ & $10 / 10$ & $8 / 8$ & $34 / 36$ & $0 / 8$ & $34 / 44$ \\
${ }^{67} \mathrm{Ga}+/ \mathrm{n}$ & $1 / 8$ & $5 / 7$ & $2 / 2$ & $8 / 17$ & $0 / 2$ & $8 / 19$ \\
$\mathrm{TBB}+/ \mathrm{n}$ & $16 / 18$ & $6 / 9$ & $8 / 8$ & $30 / 35$ & $0 / 7$ & $30 / 42$ \\
$\mathrm{CXR}+/ \mathrm{n}$ & $11 / 18$ & $8 / 10$ & $5 / 8$ & $24 / 36$ & $2 / 8$ & $26 / 44$ \\
$\mathrm{PFT}+/ \mathrm{n}$ & $4 / 12$ & $2 / 7$ & $1 / 4$ & $7 / 23$ & $1 / 5$ & $8 / 28$ \\
\hline Total & 18 & 10 & 8 & 36 & 8 & 44 \\
\hline
\end{tabular}

201Tl: thallium-201 scintigraphy; ${ }^{67} \mathrm{Ga}$ : gallium-67 scintigraphy; TBB: transbronchial biopsy; CXR: chest radiography; PFT: pulmonary function tests. R: rejection; I: infection; No: no infection or rejection; $n$ : total number of investigations performed; +: number of investigations showing positive results.

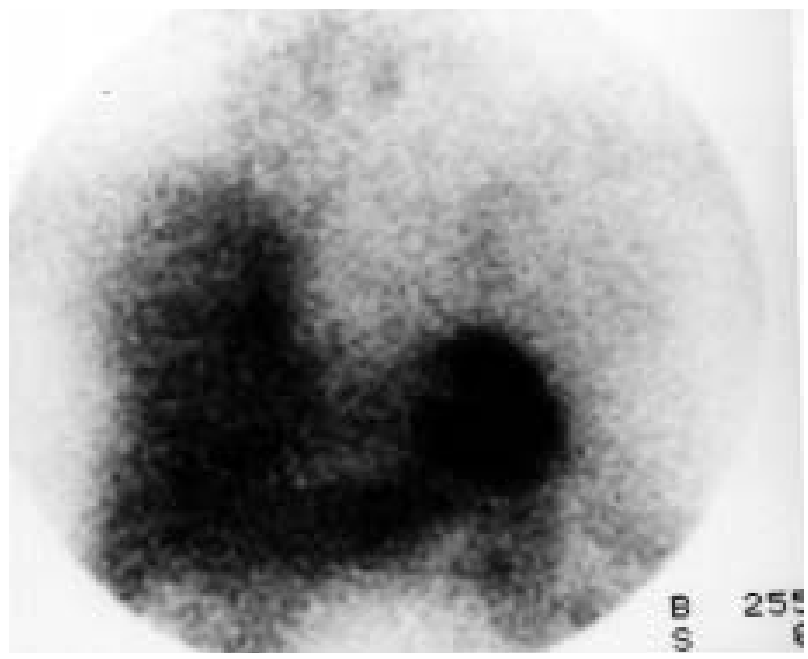

Fig. 1. - A 2+ positive thallium-201 scan in the right lung of a patient with rejection.

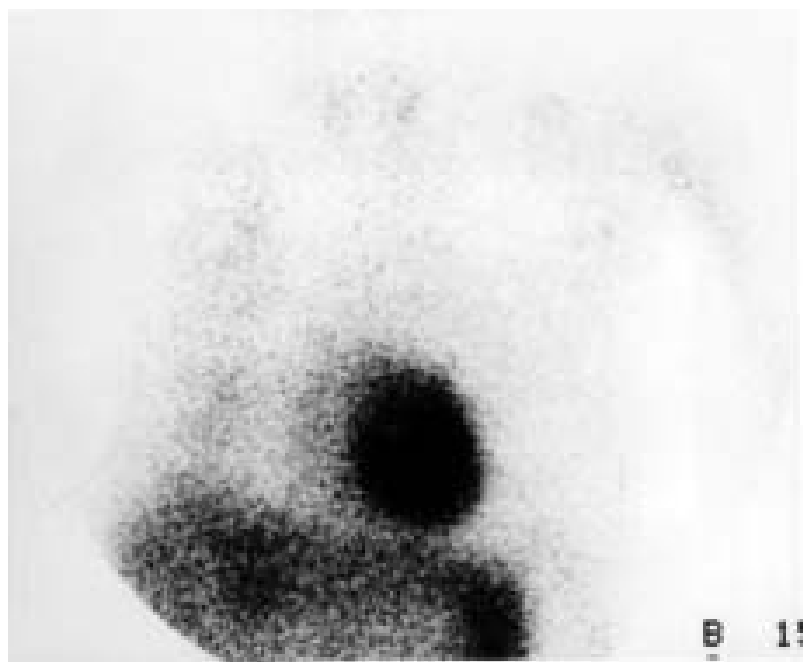

Fig. 2. - A negative thallium-201 scan in a patient without any infection or rejection.

The diagnostic reliability of each of the diagnostic procedures for detecting rejection/infection is shown in table 3 . The sensitivity of ${ }^{201} \mathrm{Tl}$ scintigraphy for diagnosing rejection/infection was $94 \%$, as compared to TBB, CXR, ${ }^{67} \mathrm{Ga}$ scan and PFT, for which it was $86,67,47$ and $30 \%$, respectively. The specificity was $100 \%$ for $201 \mathrm{Tl}$ scintigraphy, ${ }^{67} \mathrm{Ga}$ scan and $\mathrm{TBB}$, as compared to CXR and PFT, for which it was 75 and $80 \%$, respectively. The PPV was $100 \%$ for ${ }^{201} \mathrm{Tl}$ scintigraphy, ${ }^{67} \mathrm{Ga}$ scan and TBB, as compared to CXR and PFT, for which it was 92 and $87 \%$, respectively. The NPV of ${ }^{201} \mathrm{Tl}$ scintigraphy, TBB, ${ }^{67} \mathrm{Ga}$ scan, CXR and PFT were 80,58 , 18,33 and $20 \%$, respectively. The diagnostic accuracy of ${ }^{201} \mathrm{Tl}$ scintigraphy, TBB, ${ }^{67} \mathrm{Ga}$ scan, CXR and PFT was 95, 88, 53, 68 and 39\%, respectively. In this analysis, the false negative rate of TBB for diagnosing rejection/infection was $12 \%$, suggesting a significant lack of sensitivity of TBB, while the false negative rate of ${ }^{201} \mathrm{Tl}$ scintigraphy was only $5 \%$.

The concordance between ${ }^{201} \mathrm{Tl}$ scintigraphy and TBB in detecting rejection/infection is shown in table 4 . 
Table 3. - Reliability of each of the diagnostic tests for the detection of lung rejection and/or infection

\begin{tabular}{|c|c|c|c|c|c|}
\hline Diagnostic tests & $\begin{array}{c}{ }^{201} \mathrm{Tl} \\
(\mathrm{n}=44)\end{array}$ & $\begin{array}{c}\text { TBB } \\
(n=42)\end{array}$ & $\begin{array}{c}\text { CXR } \\
(\mathrm{n}=44)\end{array}$ & $\begin{array}{c}\text { PFT } \\
(\mathrm{n}=28)\end{array}$ & $\begin{array}{c}{ }^{67} \mathrm{Ga} \\
(\mathrm{n}=17)\end{array}$ \\
\hline \multicolumn{6}{|c|}{ Cases of correct test $\mathbf{n}(\%)$} \\
\hline True positive & $34(77)$ & $30(71)$ & $24(54)$ & $7 \quad(25)$ & $8(42)$ \\
\hline True negative & $8(18)$ & $4(17)$ & $6(14)$ & $4 \quad(14)$ & $2(11)$ \\
\hline \multicolumn{6}{|c|}{ Cases of test error $n(\%)$} \\
\hline False positive & 0 & 0 & $2 \quad(5)$ & $1 \quad(4)$ & 0 \\
\hline False negative & $2(5)$ & $5(12)$ & $12(27)$ & $16(57)$ & $9(47)$ \\
\hline \multicolumn{6}{|l|}{ Data analysis \% } \\
\hline PPV & 100 & 100 & 92 & 87 & 100 \\
\hline NPV & 80 & 58 & 33 & 20 & 18 \\
\hline Sensitivity & 94 & 86 & 67 & 30 & 47 \\
\hline Specificity & 100 & 100 & 75 & 80 & 100 \\
\hline Diagnostic accuracy & 95 & 88 & 68 & 39 & 53 \\
\hline
\end{tabular}

PPV: positive predictive value; NPV: negative predictive value. For further definitions see legend to table 2.

Table 4. - Concordance between 201TI and TBB in detecting lung rejection or infection $(n=42)$

${ }^{201} \mathrm{Tl}+{ }^{201} \mathrm{Tl}+{ }^{201} \mathrm{Tl}-{ }^{201} \mathrm{Tl}-$

$\mathrm{TBB}+\mathrm{TBB}-\mathrm{TBB}+\mathrm{TBB}-$

\begin{tabular}{lrrrr}
\hline Rejection or infection $(\mathrm{n}=35)$ & 29 & 4 & 1 & 1 \\
No rejection of infection $(\mathrm{n}=7)$ & 0 & 0 & 0 & 7 \\
\hline
\end{tabular}

+: positive; -: negative; ${ }^{201} \mathrm{Tl}$ : thallium-201 scintigraphy; TBB: transbronchial biopsy.

Among all episodes of rejection/infection, 29 evaluations were associated both with ${ }^{201} \mathrm{Tl}$ scintigraphy and TBB positive, four with ${ }^{201} \mathrm{Tl}$ scintigraphy positive and TBB negative, one with ${ }^{201} \mathrm{Tl}$ scintigraphy negative and TBB positive showing obliterative bronchiolitis and one both with ${ }^{201} \mathrm{Tl}$ scintigraphy and TBB negative, which was subsequently diagnosed by response to an immunosuppression regimen. Seven evaluations were without any rejection or infection, all showed a negative ${ }^{201} \mathrm{Tl}$ scintigraphy and TBB.

The sensitivities of each test for the diagnosis of isolated rejection and isolated infection are shown in table

Table 5. - Sensitivity of each test in the diagnosis of isolated rejection and isolated infection

\begin{tabular}{lcrccc}
\hline & \multicolumn{5}{c}{ Sensitivity $\%$} \\
\cline { 2 - 6 } & TBB & ${ }^{201} \mathrm{Tl}$ & ${ }^{67} \mathrm{Ga}$ & CXR & PFT \\
Rejection & 92 & 92 & 30 & 62 & 33 \\
Infection & 70 & 100 & 78 & 72 & 27 \\
\hline
\end{tabular}

For definitions see legend to table 2.
5. ${ }^{201} \mathrm{Tl}$ scintigraphy and TBB were $92 \%$ sensitive versus 62,33 and $30 \%$ for CXR, PFT and ${ }^{67} \mathrm{Ga}$ scan, respectively, in diagnosing isolated rejection. For the detection of an isolated infection, ${ }^{201} \mathrm{Tl}$ scintigraphy showed a significantly higher sensitivity of $100 \%$, while TBB, CXR, ${ }^{67} \mathrm{Ga}$ scan and PFT showed sensitivity of 70, 72, 78 and $27 \%$, respectively.

The correspondence of ${ }^{201} \mathrm{Tl}$ scintigraphy and ${ }^{67} \mathrm{Ga}$ scan in detecting lung rejection and/or infection are shown in table 6 . There were six episodes of rejection and two episodes of infection in which ${ }^{201} \mathrm{Tl}$ scintigraphy was positive and ${ }^{67} \mathrm{Ga}$ scan was negative, but no episodes of rejection or infection in which ${ }^{201} \mathrm{Tl}$ scintigraphy was negative and ${ }^{67} \mathrm{Ga}$ scan was positive, reflecting the greater sensitivity of ${ }^{201} \mathrm{Tl}$ scintigraphy. There were five episodes of infection, one episode of rejection and two episodes of rejection and infection in which both ${ }^{201} \mathrm{Tl}$ scintigraphy and ${ }^{67} \mathrm{Ga}$ scan were positive, while there was only one episode of rejection in which both were negative (diagnosed by response to empirical steroid bolus). There were two episodes without any rejection or infection in which both ${ }^{201} \mathrm{Tl}$ scintigraphy and ${ }^{67} \mathrm{Ga}$ scan were negative.

\section{Discussion}

Thallium has recently been reported to be of value in detecting the presence of inflammatory lung diseases [11]. Similarly, gallium-67 citrate scintigraphy and 111-indium lung imaging have demonstrated utility in the diagnosis of suspected lung disease, especially Pneumocystis carinii and tuberculosis in patients with human immunodeficiency virus (HIV) infection [17, 18].

Table 6. - Correspondence of ${ }^{201} \mathrm{TI}$ and ${ }^{67} \mathrm{Ga}$ in detecting lung rejection and/or infection

\begin{tabular}{|c|c|c|c|c|c|}
\hline & ${ }^{67} \mathrm{Ga}+/ 201 \mathrm{Tl}+$ & ${ }^{67} \mathrm{Ga}+/ 201 \mathrm{Tl}-$ & ${ }^{67} \mathrm{Ga}-/ 201 \mathrm{Tl}+$ & ${ }^{67} \mathrm{Ga}-/ 201 \mathrm{Tl}-$ & Total \\
\hline Rejection + & 1 & 0 & 6 & 1 & 8 \\
\hline Infection + & 5 & 0 & 2 & 0 & 7 \\
\hline $\mathrm{R} \& \mathrm{I}+$ & 2 & 0 & 0 & 0 & 2 \\
\hline No R/I & 0 & 0 & 0 & 2 & 2 \\
\hline Total & 8 & 0 & 8 & 3 & 19 \\
\hline
\end{tabular}

+: positive; -: negative; R: rejection; I: infection; ${ }^{67} \mathrm{Ga}$ : gallium-67 scan; ${ }^{201} \mathrm{Tl}$ : thallium-201 scan. 
The diagnostic application of gallium-67 has several inherent disadvantages that make it less than ideal in imaging the chest: 1) there is a prolonged delay (usually $72 \mathrm{~h}$ ), from the time of injection to the time of diagnostic imaging to allow gallium to be cleared from the blood pool; 2) the relatively large photon energy of gallium $(6-7 \mathrm{mCi})$ exposes the patient and hospital personnel to a relatively large dose of radiation (total body $=1.64$ rads); 3) it prevents the performance of subsequent nuclear studies for 10-14 days; and 4) it limits studies to the use of stationary cameras. Therefore, in contrast to gallium, nuclear imaging using thallium offers several advantages: 1 ) immediate imaging; 2 ) the much lower photon energy of thallium $(2-3 \mathrm{mCi})$ exposes the patient and hospital personnel to less radiation (total body=0.69 rads); 3) the ability to perform subsequent nuclear studies immediately; 4) the potential for the use of a portable camera facilitates its use in a critical care setting; 5) facilitation of out-patient testing since it can be completed on a single visit; 6) no potential loss of sensitivity, as with gallium in the presence of leucopenia [19]; and 7) greater sensitivity than gallium in inflammatory lung diseases [11].

While advanced stages of rejection, reflecting an alveolitis-like process, are detectable by HRCT [6], vascular injury which would be detected by scintigraphy, appears to be the most persistent if not earliest pathology, varying in severity with the intensity of the acute rejection episode [20]. Such a pathophysiological mechanism accounts for the high sensitivity of ${ }^{201} \mathrm{Tl}$ scintigraphy (92\%) observed in the present study. This is further supported by positron-emission tomographic (PET) measurements of pulmonary-transcapillary escape rate, which were reported to be elevated in patients with biopsyproven lung rejection, and decreased after immunosuppressive treatment, suggesting that pulmonary vascular permeability is, indeed, altered by the rejection/lung injury state [21].

Previously, the reported sensitivity of TBB for diagnosing rejection was $84 \%$ in one study [5] and $72 \%$ in another [9], while specificity was $100 \%$ [5]. The potential value for scintigraphy is perhaps greatest for detecting infection, since sensitivity of TBB for diagnosing opportunistic infection has been found to be only $38 \%$, with a specificity of $100 \%$ [5]. In contrast, ${ }^{201} \mathrm{Tl}$ scintigraphy had a sensitivity of $100 \%$ in this study compared to $70 \%$ from bronchoscopic specimens. Moreover, the use of TBB has an established complication rate [10], with a diagnostic yield that is operator-dependent requiring multiple specimens for optimal sensitivity, leading to increased morbidity $[4,22,23]$. Infiltrates from TBB-related haemorrhage may persist on chest radiography for up to 6 weeks, and mimic both noninfectious, lymphoproliferative and infectious processes [8]. In addition, bronchoscopy with biopsy is an invasive procedure that requires an admission (same day surgery if not overnight) and safeguards, including continuous cardiorespiratory monitoring, the presence of an anaesthetist and, particularly in paediatric patients or adults with respiratory compromise, elective endotracheal intubation. Therefore, it is not cost-effective, especially when utilized as a surveillance procedure, and carries the risk not only of morbidity but of mortality [5, 24].
The value of a sensitive noninvasive technique is further enhanced by the observation that acute rejection episodes may remain clinically silent [19]. Rejection has been reported in up to $39 \%$ of surveillance biopsies performed in the absence of clinical or physiological decline [9]. In $57 \%$ of these, the degree of rejection was more than minimal, and also of interest was the fact that clinically inapparent CMV pneumonitis was detected in $16 \%$ of these procedures [9].

It has also been found that using only histology as a "gold standard" may grossly underestimate the number of episodes of rejection [3], because of its $28 \%$ false negative rate [9]. Open lung biopsy remains an option for a definite pathological diagnosis of rejection, but recently, at least in the perioperative period, it has been reported to be of little value [25]. Whilst empirical augmentation of immunosuppression and assessment of the clinical response is sufficient to confirm the diagnosis of rejection retrospectively, it has the potential disadvantage of needlessly increasing immunosuppression [4].

Quantitative cultures have been utilized to diagnose infection because BAL has proved to be disappointing. The commonest infections in lung transplant recipients, such as CMV, Candida and Aspergillus, are colonizers more often than invasive pathogens, and in one report eventually proved to be pathogens in only 24,25 and $0 \%$ of cases, respectively [26], with a similarly poor specificity reported for viral pneumonia [27]. Similarly, BAL samples have not proved helpful for rejection; the most widely-used BAL assay has been that of lymphocyte subsets, which has a disappointing sensitivity of $<30 \%$ [28]. However, whilst the reported diagnostic sensitivity and specificity of the PSB for bacterial pneumonia ranges $60-100 \%$ [14, 29-33], its value is limited in patients receiving antibiotics [33].

Episodes of rejection or infection may be associated with a significant fall in spirometric values in single-lung transplant (SLT) recipients [3]. However, the presence of the native lung may potentially buffer the apparent magnitude of deterioration of flow rates in the donor lung that would otherwise be expected in an acute episode of graft dysfunction [3]. This is of special significance, since obstructive lung disease is currently the most common indication for lung transplantation [35]. Accordingly, the sensitivity of pulmonary function tests in diagnosing rejection or infection is poor, progressively decreasing with vascular, restrictive and obstructive disease by 39,31 and $29 \%$, respectively, for a $15 \%$ reduction in FEV1 [3]. These values are similar to those observed in the present study of 33 and $27 \%$ for rejection and infection, respectively. In addition, it has been reported that an adverse impact because of CMV infection on pulmonary function is not observed during the first year after transplantation [36].

Chest radiography has been found to be normal in $50 \%$ of early cases of rejection [4], increasing to $77 \%$ of rejection episodes occurring after the first postoperative month [37]. Similarly, a CXR is not sufficiently sensitive to detect infection, as demonstrated by one report showing no change from baseline in $65 \%$ of lung transplant recipients with CMV pneumonitis [36].

Many patients present clinically with mild dyspnoea or other respiratory symptoms that, while sensitive for rejection or infection, have a low specificity. Other signs 
of rejection, including tachypnoea, crackles, fever and/ or hypoxia, are more specific, but are absent in the majority of patients with grades 1 and 2 acute lung rejection and in early stages of infection [2]. Finally, even abnormalities in blood gas values were absent in $33 \%$ of cases of proven rejection [4]. Thus, safe and noninvasive methods, including clinical assessment [2], PFT [3], measurement of blood gas values [4], CXR [4, 5, $36,37]$, HRCT [6] and SPECT with Tc-99m macroaggregated albumin (MAA) [7] are relatively insensitive or nonspecific for diagnosing pulmonary rejection or infection.

While radionuclide imaging has been explored for the evaluation of functional and anatomical integrity in organ transplantation, its use has been limited and has focused primarily on obtaining functional or physiological information [38]. We conclude that thallium-201 scintigraphy is useful for screening single-lung transplant recipients for the detection of acute rejection and/or infection, and in addition to the advantage of immediacy it is more sensitive than gallium-67 and should complement other noninvasive diagnostic techniques, such as physical examination, CXR, and routine pulmonary function testing. In patients without evidence of clinical deterioration, the potential morbidity of bronchoscopic procedures can be avoided. An abnormal ${ }^{201} \mathrm{Tl}$ scintigraphy, even in the absence of other findings, including radiological or pulmonary function abnormalities, may prompt bronchoscopy with TBB. Whilst thallium scintigraphy lacks specificity in regard to differentiating rejection from infection, a positive thallium scan indicates either entity and strongly suggests an active process. It must be emphasized that, while ${ }^{201} \mathrm{Tl}$ scintigraphy is an extremely sensitive method for detecting an inflammatory process in the lung, unlike bronchoscopy, it is not capable of detecting a specific histological process or a specific organism causing an infection. Moreover, it does not appear to be "too sensitive" resulting in a high false positive rate.

In a preliminary study of asymptomatic lung transplant patients undergoing surveillance bronchoscopy with transbronchial biopsy, we have found the thallium scan to be positive in only one of seven patients having negative bronchoscopic findings. Further efforts are being made to assess whether ${ }^{201} \mathrm{Tl}$ scintigraphy can evaluate, both quantitatively and qualitatively, the response to empirical or specific therapy causing local or diffuse and chronic as well as acute lung injury. Potentially, the role of $201 \mathrm{Tl}$ scintigraphy may be even greater in routine long-term management strategies for surveillance. Additionally, the detection of a localized area of ${ }^{201} \mathrm{Tl}$ scintigraphy "uptake" may serve to guide PSB cultures and TBB, perhaps decreasing the need for multiple specimens, thus lowering the risk for biopsyrelated complications and reducing the chance for sampling error. This technique may also be applied to the potential donor lung to evaluate its apparent integrity in an attempt to predict the pulmonary "implantation response", which has been related to graft ischaemia.

Finally, pulmonary complications of transplant medicine are not specific for lung transplants only, and the potential value of thallium-201 scintigraphy for the detection of pulmonary infections in recipients of other solid organs and bone marrow should also be evaluated.

\section{References}

1. Chaparro C, Maurer JR, Chamgerlain D, et al. Causes of death in lung transplant recipients. J Heart Lung Transplant 1994; 13: 758-766.

2. Scott JP. The role of bronchoscopy in lung transplantation. J Bronchology 1994; 1: 135-143.

3. Becker FS, Martinez FJ, Brunsting LA, Deeb M, Flint A, Lynch JP. Limitations of spirometry in detecting rejection after single-lung transplantation. Am J Respir Crit Care Med 1994; 150: 159-166.

4. Sleiman $\mathrm{C}$, Groussard $\mathrm{O}, \mathrm{Mal} \mathrm{H}$, et al. Clinical use of transbronchial biopsy in single-lung transplantation. Transplantation 1991; 51: 927-929.

5. Higenbottam T, Stewart S, Penketh A, Wallwork J. Transbronchial lung biopsy for the diagnosis of rejection in heart-lung transplant patients. Transplantation 1988; 46: 532-539.

6. Loubeyre P, Revel D, Delignette A, Loire R, Mornex J. High resolution computed tomographic findings associated with histologically-diagnosed acute lung rejection in heart-lung transplant recipients. Chest 1995; 107: 132-138.

7. Colt HG, Cammilleri S, Khelifa F, et al. Comparison of SPECT lung perfusion with transbronchial lung biopsy after lung transplantation. Am J Respir Crit Care Med 1994; 150: 515-520.

8. Scott JP, Higenbottam TW, Clelland CA, Smyth RL, Solis E, Wallwork J. A prospective study of 204 bronchoscopies in 52 heart-lung and lung transplant recipients using TBB. J Heart Transplant 1991; 10: 626-636.

9. Trulock EP, Ettinger NA, Brunt EM, Pasque MK, Kaiser LR, Cooper JD. The role of transbronchial lung biopsy in the treatment of lung transplant recipients. Chest 1992; 102: 1049-1054.

10. Falkerson W. Current concepts: fiberoptic bronchoscopy. N Engl J Med 1984; 311: 511-515.

11. Miller JA, Lee S, Lao R, Karetzky M. Comparison of thallium-201 and gallium-67 citrate scintigraphy in the diagnosis of pulmonary disease. Chest 1995; 107: 440446.

12. Cooper JD, Billingham M, Egan T, et al. A working formulation for the standardization of nomenclature and for clinical staging of chronic dysfunction in lung allografts. J Heart Lung Transplant 1993; 12: 713-716.

13. Yousem SA, Berry GJ, Brunt EM, et al. A working formulation for the standardization of nomenclature in the diagnosis of heart and lung rejection: lung rejection study group. J Heart Transplant 1990; 9: 593-601.

14. Wimberley NW, Bass JB, Boyd BW, Kirkpatrick MB, Serio RA, Pollock HM. Use of a bronchoscopic protected catheter brush for the diagnosis of pulmonary infections. Chest 1982; 81: 556-562.

15. Annesley T, Matz K, Balogh L, Giacherio D. Liquidchromatographic analysis for cyclosporin and use of a microbe column and small sample volume. Clin Chem 1986; 32: 1407-1409.

16. Reigelman RK, Hirch RP. Studying a study and testing a test. Boston, Little Brown, 1989; pp. 151-163.

17. Santin M, Podazamczer D, Ricart I, et al. Utility of the gallium-67 citrate scan for the early diagnosis of tuberculosis in patients infected with human immunodeficiency virus. Clin Infect Dis 1995; 20: 652-656.

18. Khalkhali J, Mena J, Rauh DA, et al. 111-indiumDPTA-IgG lung imaging in patients with pulmonary and HIV infection. Chest 1995; 107: 1336-1341. 
19. Staab EV, McCartney WH. Role of gallium-67 in inflammatory disease. Semin Nucl Med 1978; 8: 219-234.

20. George EA. Radionuclide diagnosis of allograft rejection. Semin Nucl Med 1982; 12: 379-386.

21. Kaplan JD, Trulock EP, Cooper JD, Schuster DP. Pulmonary vascular permeability after lung transplantation: a positron emission tomographic study. Am Rev Respir Dis 1992; 145: 954-957.

22. Koerner SK, Hagstrom JWC, Vieth FJ. Transbronchial biopsy for the diagnosis of lung transplant rejection: comparison with needle and open lung biopsy techniques in canine lung allografts. Am Rev Respir Dis 1976; 114: 575-579.

23. Scott JP, Higenbottam TW, Clelland CA, Smyth RL, Solis W, Wallwork J. A prespective study of 204 bronchoscopies in 52 heart-lung and lung transplant recipients using transbronchial biopsies (Abstract). Am Rev Respir Dis 1990; 141: A408.

24. Scott JP, Higenbottam TW, Sharples L, et al. Risk factors for obliterative bronchiolitis in heart-lung transplant recipients. Transplantation 1991; 51: 813-817.

25. Chaparro C, Maurer JR, Chamberlain DW, Todd TR. Role of open lung biopsy for diagnosis in lung transplant recipients: ten year experience. Ann Thorac Surg 1995; 59: 928-932.

26. Pisani RJ, Wright AJ. Clinical utility of bronchoalveolar lavage in immunocompromised hosts. Mayo Clin Proc 1992; 67: 221-227.

27. Clelland CA, Higenbottam TW, Stewart S, Scott JP, Wallwork J. The histological changes in transbronchial biopsy after treatment of acute lung rejection in heartlung transplant recipients. J Pathol 1990; 161: 105-112.

28. Clelland CA, Higenbottam TW, Monk JA, Scott JP, Smyth RL, Wallwork J. Bronchoalveolar lavage lymphocytes in relation to TBB in heart-lung transplant recipients. Transplant Proc 1990; 22: 1479.
29. Lorch DG, John JF, Tomlinson JR, Miller KS, Sahn SA. Protected transbronchial needle aspiration and protected specimen brush in the diagnosis of pneumonia. Am Rev Respir Dis 1987; 136: 565-569.

30. Fagon J. Chastre J, Hance AJ, et al. Detection of nosocomial lung infection in ventilated patients. Am Rev Respir Dis 1988; 138: 110-116.

31. Chastre J, Fagon FY, Soler P, et al. Diagnosis of nosocomial pneumonia in intubated patients undergoing ventilation: comparison of the usefulness of bronchoalveolar lavage and the protected specimen brush. Am J Med 1988; 85: 499-506.

32. Chastre J, Viau F, Brun P, et al. Prospective evaluation of the protected specimen brush for the diagnosis of pulmonary infection in ventilated patients. Am Rev Respir Dis 1984; 130: 924-929.

33. Torres A, Puig De la Bellacasa J, Xaubet A, et al. Diagnostic value of quantitative cultures of bronchoalveolar lavage and telescoping plugged catheters in mechanically-ventilated patients with bacterial pneumonia. Am Rev Respir Dis 1989; 140: 306-310.

34. Ettinger NA. The role of bronchoscopy in organ transplant recipients. J Bronchology 1995; 2: 43-58.

35. Kaye MP. The registry of the international society for heart and lung transplantation: tenth official report 1993. J Heart Lung Transplant 1993; 12: 541-548.

36. Ettinger NA, Bailey TC, Trulock EP, et al. Cytomegalovirus infection and pneumonitis. Am Rev Respir Dis 1993; 147: 1017-1023.

37. Millet B, Higenbottam TW, Flower CDR, Stewart S, Wallwork J. The radiographic appearances of infection and acute rejection of the lung after heart-lung transplantation. Am Rev Respir Dis 1989; 140: 6267.

38. Shah AN. Radionuclide imaging in organ transplantation. Radiol Clin North Am 1995; 33: 473-496. 